\title{
MENA Region Transformed Media Environment and Media Convergence. UAE Case Study
}

\author{
Sameer O.A Baniyassen \\ Mass Communication Dept, Humanities and Social Sciences College, UAE \\ *Corresponding Author: Sameer O.A Baniyassen, Mass Communication Dept, Humanities and
} Social Sciences College, UAE

Received Date: 07-07-2017

Accepted Date: 15-07-2017

Published Date: 28-07-2017

\begin{abstract}
In principle, the media convergence paradigm comprises of four distinct dimensions entailing the technological, textual, social, and industrial spheres. Specifically, the technological dimension involves the combination content, communication, and computing within the systems of digital media platforms. The industrial dimension is based on the interactions among the media institutions as well as the increasing number of digitally-based companies engaging in the provision of media content. This papers aims to explore the Region Transformed Media Environment and Media Convergence specially in the United Arab Emirates.
\end{abstract}

Keywords: Media Convergence, Media Environment, UAE, New Media

\section{INTRODUCTION}

The Concept of Media Convergence It is worth noting that the concept of media convergence entails the process of multiple media platforms coming together to combine their equipment and tools towards enhancing the production and distribution of news or information (Dwyer, 2010). In essence, it demonstrates the collaboration or cooperation between diverse media platforms to create a blend of computer, telecommunications, and media industries that can eliminate the barriers to media unity (Lugmayr \& Dal, 2016). It embraces the integration of various media forms into a single digital platform. Scholars like Al-Jenaibi (2011) believed that he diversity and dynamic experience encountered through the process of media convergence enables the professionals in the sector to elaborately communicate information and tell stories (Latzer, n.d.). They can offer entertainment to the audience in a convenient manner while enhancing the interactivity of the media platforms for the unique experience. Ideally, Jin, (2011) explains that the concept of media convergence is related to the aspect of technology convergence in the sense that it entails the combination of diverse technologies used in the media system in conveying information. The technology convergence facilitates the media content production through the expansion, acceleration, and enhancing its distribution with the reduction in costs (Jacobs, 2013, Al-Jenaibi, 2014). According to the Australian Law Reform Commission (n.d), the technology convergence relies on the diversity of available media devices or gadgets that are utilized in the transmission of information and data. As such, the application of technology convergence enhances quick, safe, and convenient mechanisms of passing information to the consumers through the digital platform. Lugmayr \& Dal, 2016 indicates that the development of the cross-media content enables the media stations and professionals to provide the information in varied modes including videos, texts, audio, print, and the podcasts. Notably, this paper focuses on discussing the concepts of media convergence within the context of the MENA region, specifically in the UAE.

On the other hand, Dwyer, (2010) explains that the social dimension deals with the emergence of the social networks including the user-created contents while the textual dimension entails the fusion of media content into the transmedia model. Markedly, it is important to identify the significance of media convergence including its benefits, challenges, and the factors surrounding its utilization, application, as well as the 
strategies for improvement (Australian Law Reform Commission, n.d). In that regard, the converged media enables the recipients of the information to enjoy receiving it in a convenient mode or platform using the range of supported devices. The media convergence is associated with the benefits in enhancing the professional competence, extraction of flexible topics, as well as offering high quality of service to the consumers (Lugmayr \& Dal, 2016). It also promotes the development of new technologies in the sector while establishing comprehensive general awareness among the public regarding the information perpetrated. However, according to Jin, (2011), media convergence espouses the challenge of media ownership whereby the big media corporations and private owners take advantage of higher control over the media industry. On the other hand, it also requires the knowledge and skills in the use of the modern technologies including access to such forms of techniques in disseminating information to the consumers (Al-Jenaibi, 2015). Consequently, the converged media presents the challenge of upholding the policies, rules, and regulations pertaining to the content delivery, distribution systems whether public or private as well as the impact in the society (Latzer, n.d.). For example, it becomes difficult to control the nature or type of content that people access based on their ages and religion. It requires the determination of the items that are fit for public consumption and those for the private utility.

\section{LITERATURE REVIEW}

The Converged Media in UAE and MENA Region

Essentially, according to Ayish, (2003), the convergence of various media platforms in the UAE began in the 1990s when the diverse technologies merged into major transmission models for information transfer. The traditional media system that was under the control of the government encountered major reforms caused by the technological convergence of the Internet-oriented production models, telecommunications, and the satellite television systems (Diaa, 2014). It presented an avenue for experiencing diversity in media services with the revolution of the mechanisms for the transfer of information and communications. The development of the World Wide Web and the emergence of the satellite television systems enabled the Arab world media to offer sophisticated information on diverse platforms. The Arab government encountered challenges occasioned by the advent of the socio-political transformations associated with the evolution of the media environment (Ayish, 2003). Moreover, the new environment of the Arab media systems enhanced the capacity of the communication media to argue for the freedom of expression. In fact, it also facilitates the investment of the private entities in the media sector in the Arab countries. Notably, the UAE gained immensely from the media convergence by emerging as having the most advanced environment for the realization of the telecommunications and media systems. On the other hand, the UAE shined over the other MENA states regarding the rates of penetration of the media systems as well as the density of the telecommunications in the region. As such, it is rich in media content and diversity compared to its counterparts that are lagging behind regarding media availability or coverage. By 2003, the aspects of media convergence in the UAE took a rapid dimension as it had attained two local cables, five terrestrial telecommunications systems, and eight satellites. Remarkably, the media development experienced in the UAE realized a per capita income to a tune of 19,000 dollars, an amount that had not been encountered in the Arab World in the period. Indeed, it was a change from the diversification strategy for the national economic revenue from over-reliance on the oil industry by the UAE economy.

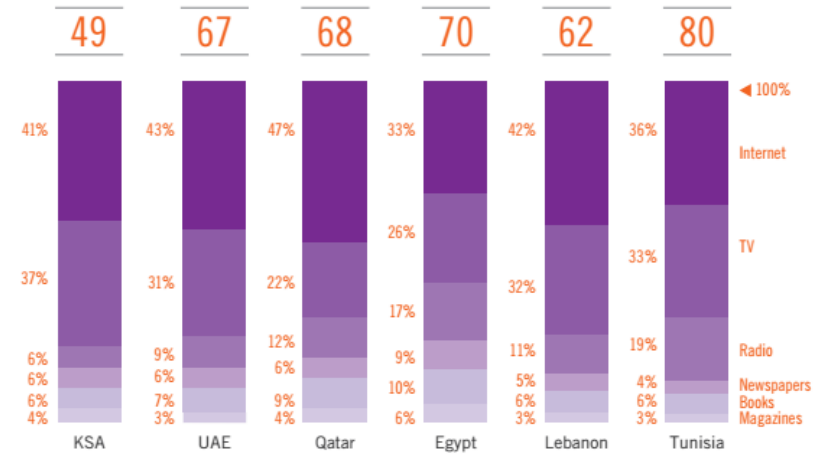

Figure1.0. Time per week for media platforms in MENA (Arab Media Outlook, n.d) 
Fundamentally, the MENA region has encountered great growth in creative energy associated with the cultural shifts in practices and preferences among the youth group. In fact, the convergence in the media sector is highly attributed to the growing demand for Arabic content among the young people. For example, the various media platforms have benefitted from the development of the mobile technology that facilitates the access to information (Diaa, 2014, Al-Jenaibi, 2011). On the other hand, the investors have identified the opportunities created by the development of the digital and paid media platforms. As such, the investors are able to modify their business models while assessing the quality of the local content as well as evaluating the chances of surviving in the business environment. Principally, the development of the new media platforms has been anchored on the spheres of education, talent or skills, work environment or infrastructure, and the financial factors. The young people play a pivotal role in the development of the new media entailing the convergence of diverse forms of media into the major platforms for communications or information transfers as well as entertainment (Ayish, 2003). As such, the cumulative combination of the creative energy among the youths in the Arabic countries helps to enhance the international and large regional players. According to the Arab Media Outlook (n.d), younger demographics in the MENA regions whereby 68 percent of the people are below the age of 35 years old contributed immensely in propelling the growth in the new media industry. The higher literacy levels among the young generation facilitate the uptake of the digital media content, and the consumption of the information delivered.

\section{UAE Total Media Market}
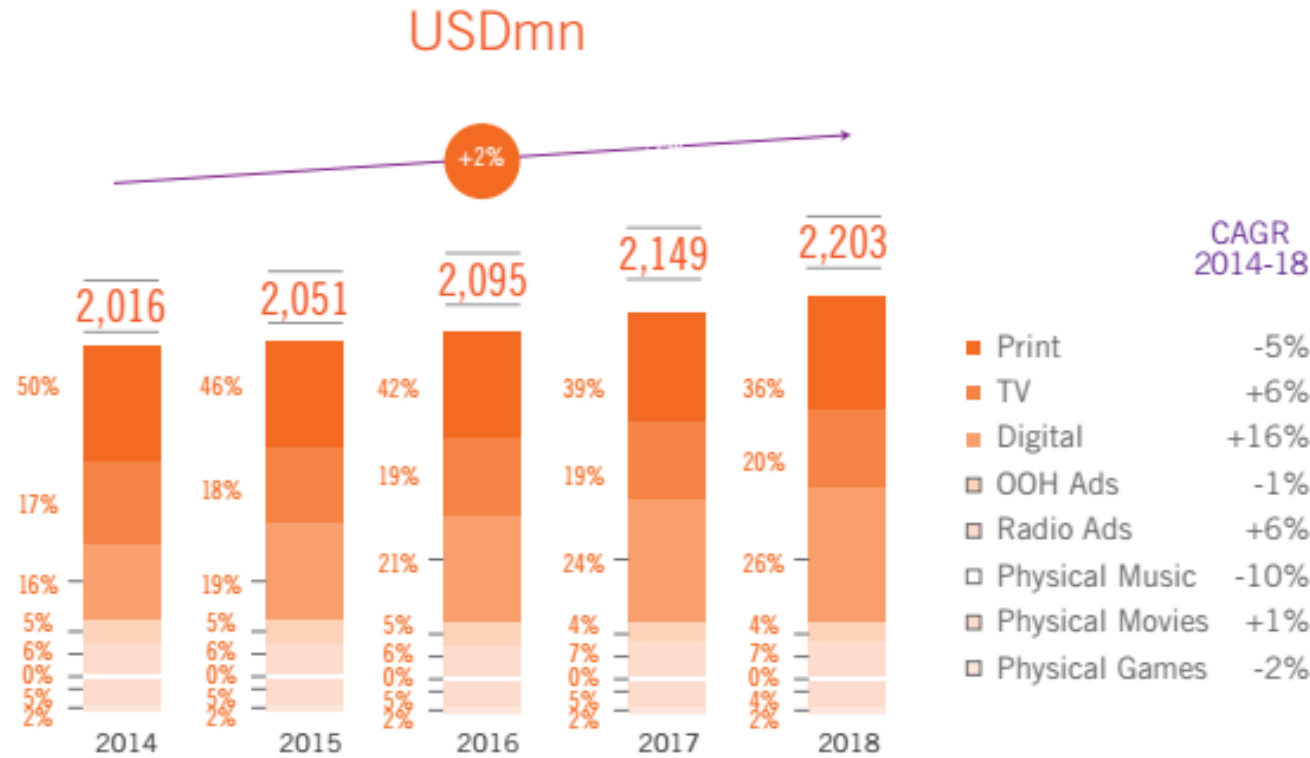

Figure1.1. UAE total media market (Arab Media Outlook, n.d)

\section{MANAGEMENT TheORIES FOR THE CONVERGED MEDIA}

\section{Strategic Management Theory}

Notably, the management of the converged media entails an integration of the media industry features and the strategic management theories that are influenced by politics, economics, or other social factors. Hollifield, et al. (2016) indicates that the media management embraces various theories that are used in understanding the modalities and techniques applied in gaining control over the activities of the media including mass communication. In essence, the management of the converged media looks into the elements of media market concentration, media regulations, available strategic options, as well as the adaptation to the changing market conditions. Lowe, (2016) explains that the management of the converged media utilizes the approaches of SCP (structureconduct-performance) and RBV (resource-based view) frameworks. Specifically, the SCP deals with the media industry structure while linking it to the performance or conduct of the organization (Mierzejewska, n.d). It espouses that the structural features like the size, number, or location have influences on the conduct of the 
organization thereby affecting performance. Ideally, the performance of the organization is based on the economics, and the social responsibility attributes like meriting the social norms or protecting the democratic space. On the other hand, the RBV framework focuses on the available resources for the organization including its unique skills that enhance its competitive edge for the survival of the organization (Mierzejewska, n.d). Consequently, the organization can also rely on the ecological niche whereby the media industry sectors occupy their operational space for protection against stiff competition. For example, the converged media that combines the various platforms of information transfer like the internet, video, print, or audio can specialize in the unique areas for survival. In principle, the converged media addresses the concerns of the organization regarding new product development, market entry techniques, jointventure management, and the establishment of brands (Latzer, n.d., Al-Jenaibi, 2014). Such initiatives are guided by the existing regulatory policies, social environments, and the economic features for operations (Lowe, 2016).

\section{Structural Theory}

Further, the management of the converged media looks into the elements of the organizational structure that are associated with the performance outcomes (Mierzejewska, n.d). In that regard, it applies the concepts of the structural contingency theory that demonstrates the impact of the organizational structures on the performance outcomes. The function of the organization is to identify the structural systems that enhance efficiency while considering the economic rationality for optimal financial performance. Hollifield, et al. (2016) explains that the increasing media consolidation complicates the organizational structures of the media systems while exposing the performance variances among the media industry players. As such, it applies the Transnational Media Management Theory that articulates the entry processes of the media industries into the global market. On the other hand, the ownership structures for various media corporations influences the priorities of the organization as well as the media content delivery. For example, some of the print media systems engage in contents that espouse the editorial views on pressing issues, preferred political candidates, conflict coverage, and the coverage of the hard news.

\section{Transnational Media Management Theory}

Moreover, the management of the converged media looks into the concepts of private ownership versus the public ownership models. As such, it focuses on the investor returns along the lenses of financial markets while controlling a number of resources injected into the newsrooms by the public media. It affects the product qualities of the entertainment or news as well as other aspects of content production (Lowe, 2016). Additionally, the organizational structures of the converged media also affect the priorities and professional values of the news managers. In that regard, it influences the decisions on the type of news and a number of resources that can be injected into the news coverage activities.

\section{Organizational Culture Theory in the Converged Media}

It is worth noting that the application of the organizational culture theory in the converged media influences the priorities, decisions, conduct, and the outcomes of the media industry players. In that regard, Fuchs, (2014) indicates that the organizational culture can have either a positive or a negative effect on the performance of the organization. The organizational culture entails the shared knowledge, practices, and values that the players in the media industry encounter and pass to the new entrants. It affects the processes within the organization, the output performance, as well as the survival chances in the competitive market environments. Essentially, various factors influence the organizational culture in the media industry such as the national culture, the leadership, and the general operational environments (Jan 2009). The operating environment entails the competitive market environment, the production technologies utilized, and the primary business line for the company. The media industry players with similar operational lines have a shared characteristics regarding organizational cultures occasioned by the similarities in the technologies, markets, and products. On the other hand, there are great differences in the organizational cultures between media industry players that engage in distinct ventures or product provisions. Furthermore, the organizational cultures in the converged media can be broken down into subcultures such as the occupational and professional subcultures (Fuchs, 2014). The professional subcultures encompass the individuals with similar occupational skills despite the differences in the 
companies served. Jan 2009) explains that the occupational subcultures influence the climate and the organizational conduct in the company thereby affecting the commitment to service. On a similar model, the corporate culture also affects the adaptability of the media stations to the changes in the operational market conditions.

\section{Leadership Theory in the Converged Media}

Essentially, the management theory of the converged media requires proper leadership from the executive in managing as well as controlling the media companies. The concept of leadership theory in the spheres of media industry entails the provision of the guide towards the moral behaviors of the people involved. As such, the leadership concepts entail the decision-making styles, leadership traits or styles, change management, leadership contingencies, communication styles, as well as the power plays in the organization (Johns et al., 2014). Moreover, the leadership focuses on addressing the organizational problems, demonstrating the organizational priorities or values, as well as establishing the association between leadership and the perceived change (Jacobs, 2013). The leadership in the converged media puts into consideration the need for the motivation of the journalists geared towards enhancing job satisfaction. The satisfaction levels among the journalists are based on the capacity to produce quality news that informs the public of current issues. Other factors contributing to the journalist satisfaction include good association with the managers, high social status, as well as the autonomy at work. The media industry encounters tremendous levels of changes technical, regulatory, and economic environments leading to the need for elaborate change management strategies (Jan 2009).

\section{Challenges in Management of Converged Media}

The new operating conditions for the media professionals present immense challenges with the upsurge of the media products including their effects on the culture and the general life. The challenges regarding the need for recognition by the thirsty audience and the payment that is based on the content produced by the company affects the operations of the journalists (Iosifidis, 2011). There are challenges in meeting the interests of the dual-product marketplace, especially concerning the content strategy. For example, the balance between satisfying the largest audience or many customers against the interests of the advertisers.
The emergence of the digitalized systems propels new elements of consumption patterns whereby the consumer choices are altered with differences in preferences for products. The rising ranges of the distribution platforms coupled with the changes in the nature of contents for the platforms are associated with the increased specialized content in the media industry. In that regard, there is fragmentation of the media consumption patterns as it spread through the varied platforms leading to new modes of behavior among the media consumers. The fragmentation of the media consumption patterns complicates the estimations or measurements of the target audience for the access by the advertisers. The media purchase decisions re influenced by the rise of the new distribution channels and the digitalization of the media systems. Ideally, the convergence of the media platforms often fails to take cognizance of the niche depth and breadth of the available content in the marketplace (Johns et al., 2014). The advancement of the media industry is hampered by the disconnect between the media business and the academic practice of problembased research.

The MENA region media encounters similar challenges regarding the content delivery and service provision to the audience. Guaaybess, (2013) indicates that the media markets in the MENA region are considered to be leapfrogging by jumping directly to the mobile applications without spending long durations in the utilization of the PCs. As such, the publishers encounter the challenges of accruing revenue from the desktop interface since the majority of the youth population receive information on the mobile screens. On the other hand, the media demand in the MENA region is based on the per capita consumption that focuses on the oil prices (Āyish \& Mellor, 2015). As such, the low oil prices influences the spending patterns of the consumers thereby triggering the macroeconomic metrics of the media industry. The impact of the diversities in the media regulations in the midst of the unification of the media consumption trends represents other elements of challenges in the MENA region. Ideally, the regulators lag in the operational and administrative phases behind the changing landscape of improved frameworks and new models of governing apparatuses. Additionally, the demographic equations of the population growth rate are incongruent with the scales of developed markets for the media products. 


\section{Economics of the Converged Media}

Fundamentally, the economics of the converged media entails the study of the micro and macroeconomic elements of the mass media industries of companies (Doyle, 2013). It relies on the application of various economic principles, concepts, as well as economic theories in the attainment of such mass media elements. Essentially, the emergence of the concepts of media economics is attributable to the increased concentration of media platforms with their enhanced consolidations (Iosifidis, 2011). The macroeconomic elements in media economics entail the attributes such as the capital markets and labor including the regulatory or policy concerns affecting media operations. The microeconomic elements entail the use of the strategies such as the industrial organization model that is based on specified markets through processes like SCP (StructureConduct-Performance). It is worth noting that the development of the media economics concepts relies on the diverse change drivers such as the sociocultural development, globalization, regulations, and technology. The technology facilitates the exhibition, distribution, and creation of the media content delivered to the consumers. As such, Doyle, (2013) explains that the technology enhances the performance of the media industries including their competitiveness. For example, the use of computing technologies enhanced worked efficiency while saving the space used for storage of papers. Consequently, Albarran, (n.d.) explains that the reliance on the technology in converged media promoted the realization of World Wide Web for the internet, the satellite systems for digital channels, and the social media. On the other hand, the concept of globalization in the converged media entails the production of the contents intended for the global audiences. However, it faces strains in the levels of regulations for various countries that receive the products despite the increased profit margins from the advertisers. Consequently, the sociocultural developments influence the converged media through the demographic changes that require the redesign of the contents (Albarran, n.d.).

The macroeconomic environments of the MENA regions including the UAE are influenced by the demographic composition, population or economic growth, digitization, and the consumer expenditures (Guaaybess, 2013). For example, the young generations that dominate the region demonstrate their preference for the type of content that suits them. They have the liking for the emergent technologies such as the use of tablets, smartphones, or the phablets for their digital consumption (Āyish \& Mellor, 2015). The use of such technologies embraces the concepts of new product development theory that utilizes the innovations or new technologies as important weapons for a competitive market. Subsequently, the media institutions can deploy the diffusion theory that identifies the response of the consumers to the innovations or technologies.

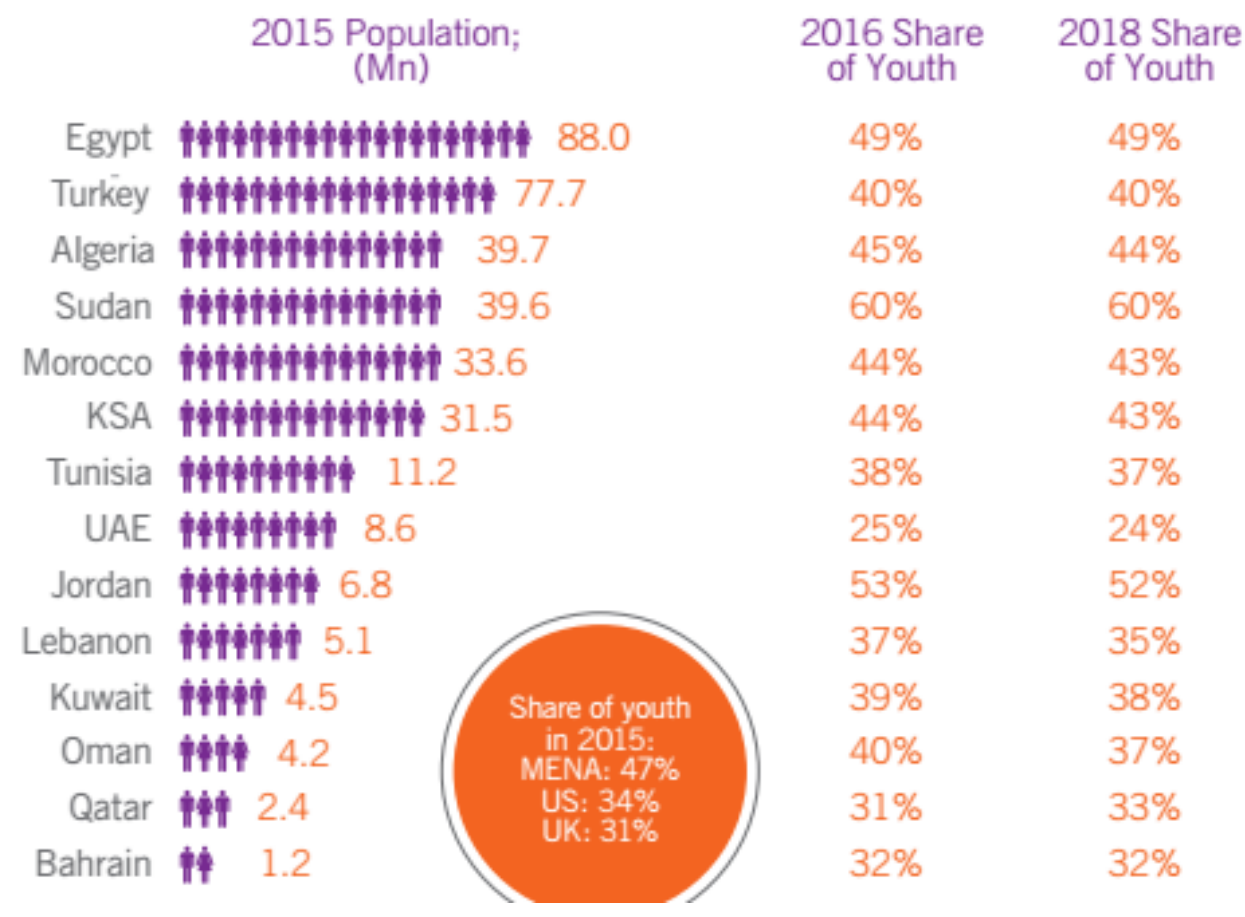

Figure1.2. MENA Population and Share of Youth (Arab Media Outlook, n.d) Conclusion 
It is established that the concept of media convergence demonstrates the collaboration or cooperation between diverse media platforms to create a blend of computer, telecommunications, and media industries that can eliminate the barriers to media unity. It embraces the integration of various media forms into a single digital platform. Moreover, the media convergence paradigm comprises of four distinct dimensions entailing the technological, textual, social, and industrial spheres. The media convergence is associated with the benefits in enhancing the professional competence, extraction of flexible topics, as well as offering high quality of service to the consumers. Specifically, the convergence of various media platforms in the UAE began in the 1990s when the diverse technologies merged into major transmission models for information transfer. On the other hand, the Arab government encountered challenges occasioned by the advent of the socio-political transformations associated with the evolution of the media environment. It is worth noting that the management of the converged media entails an integration of the media industry features and the strategic management theories that are influenced by politics, economics, or other social factors. Consequently, the management of the converged media looks into the elements of the organizational structure that are associated with the performance outcomes.

\section{REFERENCES}

[1] Albarran, A. (n.d.). Media Economics. The SAGE Handbook of Media Studies, 291-308. doi:10.4135/9781412976077.n15

[2] Al-Jenaibi, B. (2011). The scope and impact of workplace diversity in the United Arab Emirates-An initial study. Acta Universitatis Danubius. Communicatio, 5(1).

[3] Al-Jenaibi, B. (2014). Comparing the roles of PR practitioners in the public and private sectors in the UAE. International Journal of Information Systems and Social Change (IJISSC), 5(3), 64-76.

[4] Al-Jenaibi, B. (2014). Research practices in public relations organizations in the United Arab Emirates. International Journal of Customer Relationship Marketing and Management (IJCRMM), 5(3), 14-31.

[5] Al Jenaibi, B. (2011). Job Satisfaction: Comparisons among Diverse Public Organizations in the UAE. Management Science and Engineering, 5(2), 53.
[6] Al-Jenaibi, B. (2008). The effects of media campaigns on different cultures. Proceedings of World.

[7] Al-Jenaibi, B. (2015). E-collaboration. public relations and crises management in UAE Organizations. International Journal of ECollaboration, 11(3), 10-28.

[8] Arab Media Outlook (n.d). Arab Media Outlook 2016-2018. Youth, Content, and Digital Media. Fifth Edition.

[9] Australian Law Reform Commission (n.d). Media convergence and the transformed media environment. Retrieved April 7, 2017, from http://www.alrc.gov.au/publications/3-mediaconvergence-and-transformed-media-enviro $\mathrm{nm}$ ent/media-convergence-and-transform- 0

[10] Āyish, M. I., \& Mellor, N. (2015). Reporting in the MENA region: Cyber engagement and panArab social media. Lanham: Rowman \& Littlefield.

[11] Ayish, M. I. (2003). Media Convergence in the United Arab Emirates: A Survey of Evolving Patterns. Convergence: The International Journal of Research into New Media Technologies, 9(3), 77-87. doi:10.1177/135485650300900306.

[12] Diaa, S. (March 18, 2014). Media convergence in the Middle East challenged by mindset. GulfNews.com. Retrieved April 7, 2017, from http://gulfnews.com/business/sectors/technolog $\mathrm{y} /$ media-convergence-in-middle-east-challenge d-by-mindset-1.1305733

[13] Doyle, G. (2013). Understanding Media Economics. London: SAGE Publications Ltd.

[14] Dwyer, T. (2010). Media convergence. Maidenhead: Open University Press.

[15] Fuchs, C. (2014). Social media: A critical introduction. Los Angeles : SAGE.

[16] Guaaybess, T. (2013). National broadcasting and state policy in Arab countries. Houndmills, Basingstoke, Hampshire: Palgrave Macmillan.

[17] Hollifield, C. A., Wicks, J. L. B., Sylvie, G., \& Lowrey, W. (2016). Media management: A casebook approach. New York: Routledge.

[18] Iosifidis, P. (2011). Global media and communication policy. Houndmills, Basingstoke, Hampshire: Palgrave Macmillan.

[19] Jacobs G. (February 25, 2013). The Role of Media Convergence in Digital Marketing. Retrieved April 8, 2017, from http://www.targetmarketingmag.com/article/5things-all-retailers-should-know-about-theirdata/all/

[20] Jan, M. (2009). Globalization of Media: Key Issues and Dimensions. Department of Mass Communication, Gomal University. European Journal of Scientific Research. 
MENA Region Transformed Media Environment and Media Convergence. UAE Case Study

[21] Jin, D. Y. (2011). Global media convergence and cultural transformation: Emerging social patterns and characteristics. Hershey, PA: Information Science Reference.

[22] Johns, M. D., Chen, S.-L., \& Terlip, L. A. (2014). Symbolic interaction and new social media. Bingley, U.K: Emerald.

[23] Latzer, M. F. (n.d.). Media convergence. Handbook on the Digital Creative Economy, 123-133. doi:10.4337/9781781004876.00022

[24] Lowe, G. F. (2016). Introduction: What's So Special About Media Management? Managing Media Firms and Industries, 1-20. doi:10.1007/978-3-319-08515-9_1.
[25] Lugmayr, A., \& Dal, Z. C. (2016). Media Convergence Handbook - Vol. 2: Firms and User Perspectives. Berlin, Heidelberg: Springer Berlin Heidelberg.

[26] Lugmayr, A., \& Dal, Z. C. (2016). Media Convergence Handbook - Vol. 1. (Media Business and Innovation.) Berlin, Heidelberg: Springer Berlin Heidelberg.

[27] Mierzejewska, B. I. (n.d). Media Management in Theory and Pr actice.

Citation: Sameer O.A, Baniyassen."MENA Region Transformed Media Environment and Media Convergence. UAE Case Study." International Journal of Research in Humanities and Social Studies, vol 4, no. 6, 2017, pp. 1-8.

Copyright: () Sameer O.A, Baniyassen.. This is an open-access article distributed under the terms of the Creative Commons Attribution License, which permits unrestricted use, distribution, and reproduction in any medium, provided the original author and source are credited. 